\title{
Aproveitamento térmico de coletor solar na desinfestação de substrato
}

\section{Thermal utilization of solar collector in substrate disinfestation}

\author{
Ronaldo Antonio dos Santos ${ }^{(\mathbb{D})}{ }^{1}$, Eusímio Felisbino Fraga Júnior ${ }^{(\mathbb{D} 2}{ }^{2}$, Vanessa Andaló ${ }^{(\mathbb{D})}{ }^{3}$; \\ Daniel Martins da Silva ${ }^{4}$
}

${ }^{1}$ Professor Associado, Universidade Federal de São Carlos, Araras, São Paulo. E-mail: santosra@ ufscar.br; ${ }^{2}$ Professor Adjunto, Universidade Federal de Uberlândia, Monte Carmelo, Minas Gerais. E-mail: eusimiofraga @ufu.br; ${ }^{3}$ Professora Associada, Universidade Federal de Uberlândia, Monte Carmelo, Minas Gerais. E-mail: vanessaandalo@ufu.br; ${ }^{4}$ Técnico de Laboratório, Universidade Federal de Uberlândia, Monte Carmelo, Minas Gerais. E-mail: dmsilva@ ufu.br.

\section{N O T A}

Recebido: 24/09/2020

Aprovado: 04/03/2021

Palavras-chave:

Controle de pragas

Tratamento alternativo

Conversão energética

\begin{abstract}
R E S U M O
A desinfestação do substrato torna-se obrigatória na produção de mudas sadias e com vigor. No entanto, o tratamento convencional com agroquímicos pode ser insatisfatório, devido aos custos e aos riscos de vácuo biológico e intoxicação. Para minimizar essas limitações, a solarização surge como uma técnica potencialmente viável. Por conseguinte, esse trabalho avaliou a conversão energética de um coletor solar e a sua capacidade de desinfestação de substrato com grilo (Gryllus assimilis (Fabr. 1775)). O equipamento foi construído com uma caixa de madeirite, com seis tubos de aço galvanizado em seu interior. A face da caixa voltada para o Sol possuía vidro transparente, que permitia a entrada de radiação solar de ondas curtas e restringia a saída de massas de ar quente. Empregou-se o delineamento experimental inteiramente casualizado, com quatro tratamento de exposição à radiação solar, cada um com cinco repetições. Durante o experimento, constatou-se que a temperatura máxima do substrato foi de $70,4^{\circ} \mathrm{C}$, com uma amplitude térmica máxima de $38,6^{\circ} \mathrm{C}$, entre o interior e exterior do equipamento. A variação térmica, por unidade de radiação solar incidente atingiu valor máximo de $1,61^{\circ} \mathrm{C} \cdot \mathrm{W}^{-1} \cdot \mathrm{m}^{-2}$. O extermínio mais rápido dos insetos ocorreu com duas horas de exposição à radiação solar. As temperaturas do substrato no interior do coletor solar e da testemunha, foram em média de 60,4 e $25,0{ }^{\circ} \mathrm{C}$, respectivamente.
\end{abstract}

\section{A B S T R A C T}

Key words:

Pest control

Alternative treatment

Energy conversion
Disinfestation of the substrate is mandatory in the production of healthy and vigorous seedlings. However, conventional treatment with agrochemicals can be unsatisfactory, due to the costs and risks of biological vacuum and intoxication. To minimize these limitations, solarization emerges as a potentially viable technique. Therefore, this work evaluated the energy conversion of a solar collector and its capacity for disinfesting substrate with cricket (Gryllus assimilis (Fabr. 1775)). The equipment was built with a wooden box, with six galvanized steel tubes inside. The face of the box facing the sun had transparent glass, which allowed the entry of shortwave solar radiation and restricted the outflow of hot air masses. A completely randomized experimental design was used, with four solar radiation exposure treatments, each with five replications. During the experiment, it was found that the maximum temperature of the substrate was $70.4{ }^{\circ} \mathrm{C}$, with a maximum thermal amplitude of $38.6^{\circ} \mathrm{C}$, between the interior and exterior of the equipment. The thermal variation, per unit of incident solar radiation, reached a maximum value of $1.61{ }^{\circ} \mathrm{C} . \mathrm{W}^{-1} \cdot \mathrm{m}^{-2}$. The quickest extermination of the insects occurred with two hours of exposure to solar radiation. The substrate temperatures inside the solar collector and the control, were on average 60.4 and $25.0{ }^{\circ} \mathrm{C}$, respectively.

\section{INTRODUÇÃO}

O substrato é um dos insumos mais importantes na produção de plantas envasadas de qualidade (SOUZA, 2000), sendo que a presença de plantas daninhas, nematoides, doenças e/ou pragas neste meio de cultivo tem sido uma das principais causas de significativos prejuízos e insucessos, como na propagação de alface (SALA et al, 2008), cafeeiro (MIRANDA et al., 2006), citros (CARVALHO et al., 2019), erva-mate (POLETTO et al., 2015), eucalipto (MAFIA; ALFENAS;

\section{Revista Verde}

ISSN 1981-8203

Pombal, Paraíba, Brasil v. 16, n.2, abr.-jun, p.219-223, 2021 doi: $10.18378 /$ rvads.v16i2.8461 
FERREIRA, 2014; COELHO et al., 2019), rúcula (COLOMBARI et al., 2018), tomateiro (KHAN et al., 2020), entre outras culturas.

De fato, uma pequena quantidade de substrato contaminado pode ser suficiente para limitar o potencial produtivo de extensas áreas agrícolas, ao atuar como fonte de disseminação de material contaminado e produzir mudas de baixa qualidade, desuniformes, com menor vigor e sanidade.

Este dano é ainda mais significativo em se tratando de culturas perenes, uma vez que, o potencial produtivo e a longevidade destas serão conhecidos, geralmente, somente anos após o transplantio para o campo, com prejuízos persistindo ao longo de toda a vida útil da planta.

Atualmente, o tratamento convencional de substratos consiste no emprego de agrotóxicos que, além de aumentar os custos de produção, são geralmente tóxicos e trazem riscos de contaminação do homem, fauna, flora, solo e recursos hídricos, tornando-se, em certos casos, inviáveis do ponto de vista técnico e/ou econômico.

Outra limitação do tratamento de substratos com agrotóxicos consiste no fato de que este não são seletivos e podem provocar a esterilização ou "vácuo biológico", tornando o substrato sem vida, o que, no caso de uma reinfestação, permitiria a livre multiplicação de pragas e patógeno, devido à ausência de antagonistas (GHINI, 1997).

Com escassos defensivos registrados e disponíveis para o seu controle, o grilo, Gryllus assimilis (Fabricius) (Orthoptera: Gryllidae) é um inseto com cerca de $2,5 \mathrm{~cm}$ de comprimento, que se abriga durante o dia em ambientes escuros e úmidos, como em tocas, sob pedras, tocos e restos culturais, apresentando hábitos predominantemente noturnos. Sendo ortópteros onívoros, se alimentam principalmente de folhas, caule e raízes de mudas jovens e tenras (MICHEREFF FILHO et al., 2013; SALVADORI, et al., 2013).

Por serem insetos altamente prolíferos (BARBOSA et al., 2009) e de difícil controle, sobretudo em locais de baixa incidência de predadores, como nos viveiros de mudas (MASSON et al., 2020), os grilos têm se tornado frequentes em viveiros, com significativos danos e prejuízo na produção de mudas, em diversas regiões do Brasil (BARBOSA et al., 2009).

Diante das limitações do tratamento com agrotóxicos, o emprego da energia solar surge como uma alternativa potencialmente viável e promissora, ainda mais se considerado que a incidência de radiação solar é abundante no Brasil, durante o ano todo.

Comumente, no país se registram irradiâncias médias anuais relativamente uniformes e altas, com valores máximo de $6,5 \mathrm{~kW} \cdot \mathrm{h}^{-1} \cdot \mathrm{m}^{-2}$, mensurado na Bahia, e mínimo de $4,25 \mathrm{~kW} \cdot \mathrm{h}^{-1} \cdot \mathrm{m}^{-}$ ${ }^{2}$, registrado em Santa Catarina (PEREIRA et al., 2006).

Embora a disponibilidade de radiação solar seja considerada abundante no Brasil, o seu emprego ainda é incipiente, sobretudo quando comparado as principais matrizes energéticas brasileiras (BRASIL, 2019), estando limitado principalmente aos aquecedores e painéis solares.

Contudo, alguns estudos têm demonstrado a viabilidade e vantagens do emprego da energia solar em atividades antrópicas, como na agricultura, para a geração de energia (FACÃO, 2004), aquecimento de água (SOUZA FILHO, 2008), desidratação de frutas (WEIRICH NETO et al., 2016), desinfestação de pragas de grãos armazenados (MEKASHA et al., 2006; ABDULLAHI et al., 2017) e controle de plantas daninhas, nematoides, pragas e patógenos do solo (GHINI, 1997), dentre outras aplicações.

Por conseguinte, esse estudo objetivou quantificar a conversão energética de um coletor solar e a sua capacidade de desinfestação de substrato, empregado na propagação de culturas.

\section{MATERIAL E MÉTODOS}

Para a realização desse estudo, foi construído um coletor solar, com base nas sugestões de Ghini (1997), empregando-se materiais acessíveis e de baixo custo.

$\mathrm{O}$ equipamento possui uma caixa de madeirite, também denominado compensado naval, com dimensões de $1,0 \times 1,55 \times 0,3 \mathrm{~m}$ de largura, comprimento e altura, respectivamente, sustentada por suportes triangulares, que mantem a face superior inclinada, perpendicularmente a incidência da radiação solar, de acordo com a data do ano e declinação solar (Figura 1).

Ao longo dos dias de tratamento do substrato, o coletor também era movimentado manualmente, acompanhando o movimento aparente do Sol, o que permitiu manter o plano de vidro sempre perpendicular a incidência dos raios solares.

Os tubos, que acomodam o substrato durante o tratamento térmico, possuem $0,15 \mathrm{~m}$ de diâmetro e foram moldados em calandra, utilizando-se chapas de aço galvanizado, de $1,25 \mathrm{~mm}$ de espessura. Com comportas em ambas as extremidades, presas cada uma por dois parafusos com porcas borboleta, que permitem o enchimento/esvaziamento do material, os seis tubos do equipamento permitem o tratamento térmico de até $0,106 \mathrm{~m}^{3}$ de substrato (Figura 1).

A face da caixa voltada para o Sol recebeu um plano de vidro liso e transparente, colado com cola de silicone, que minimiza a saída das massas de ar aquecidas no seu interior e a perda de calor do protótipo para exterior, aumentando assim a sua eficiência (Figura 1).

Com o objetivo de minimizar a reflexão e maximizar a absorção da irradiância solar incidente sobre o equipamento, promovendo assim o aumento da sua eficiência, optou-se por pintá-lo totalmente com tinta preta fosca, de até $600^{\circ} \mathrm{C}$ de resistência, excluindo-se o plano de vidro, que permaneceu transparente.

A avaliação da conversão energética e da capacidade de desinfestação do equipamento foi realizada nas dependências do campus Araras - UFU, localizado no município mineiro de Monte Carmelo. De acordo com Oliveira (2010), essa região possui um clima do tipo Cwa, na classificação de Köppen, com $22^{\circ} \mathrm{C}$ de temperatura média anual e $1.500 \mathrm{~mm}$ de precipitação pluvial média anual, distribuída nos seis meses mais quente do ano.

A temperatura do substrato foi monitorada por um termômetro digital de infravermelho (Mensura $\left.{ }^{\circledR}\right)$, enquanto os dados de temperatura do ar e irradiância solar incidente foram mensurados ao lado do coletor solar, a dois metros de altura, em relação nível do solo, por uma estação meteorológica automática, composta por datalogger CR1000 (Campbell Scientific $\left.{ }^{\circledR}\right)$, piranômetro CMP3 (Kipp \& Zonen®) e termo-higrômetro HygroVUE (Campbell Scientific $\left.{ }^{\circledR}\right)$, instalado em abrigo térmico de seis pratos, instalada nas coordenadas geográficas de $18^{\circ} 43^{\prime}$ 
de latitude Sul e $47^{\circ} 31^{\prime}$ de longitude Oeste de Greenwich, com 880 metros de altitude média.

Os grilos adultos foram introduzidos propositalmente em substrato comercial (Bioplant $\left.{ }^{\circledR}\right)$, composto por turfa de
Sphagnum, fibra de coco, casca de arroz, casca de pinus e vermiculita. Em seguida, utilizou-se parte desse material infestado para abastecer totalmente os tubos do coletor solar.

Figura 1. Face do coletor, com plano de vidro, que recebe a irradiância solar incidente e comportas inferiores para descarga do substrato (A), suportes triangulares da caixa e entrada dos tubos de aço galvanizado (B) e comportas para enchimento do equipamento (C).

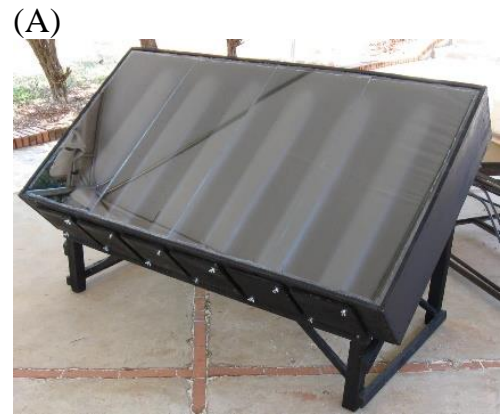

(B)

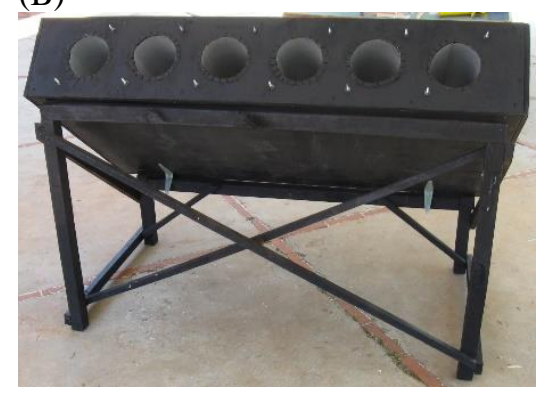

(C)

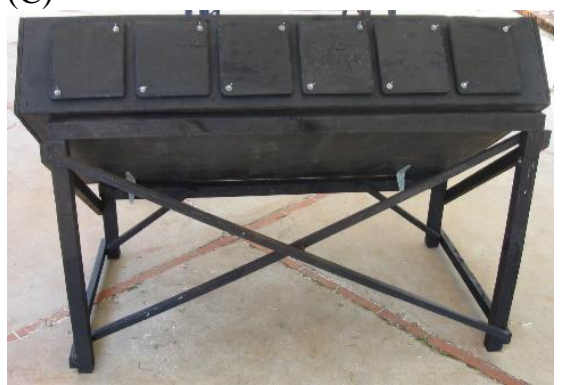

Uma amostra desse substrato, sem grilo-preto, foi colocada em ambiente protegido da irradiação solar, sendo assim considerada testemunha, na avaliação térmica do coletor solar.

O delineamento experimental empregado foi o inteiramente casualizado, com quatro tratamentos, sendo esses 1, 2, 3 e 4 horas de absorção de irradiação solar incidente, e cinco repetições.

Os dados obtidos foram posteriormente submetidos à análise de variância e as médias comparadas no teste de Tukey $(\mathrm{P}<0,5)$, empregando-se o software estatístico Sisvar (FERREIRA, 2019).

\section{RESULTADOS E DISCUSSÃO}

Como podem ser observadas na Figura 2, a temperatura mínima do ar foi de $20,0^{\circ} \mathrm{C}$, enquanto a máxima e média foram de 32,1 e $28,4{ }^{\circ} \mathrm{C}$, respectivamente. Geralmente, as proteínas e enzimas de grande importância para o metabolismo celular dos organismos fitopatogênicos são desnaturadas pelo calor, tornando-se letal para maioria quando a temperatura se encontra na faixa entre 45 e $60{ }^{\circ} \mathrm{C}$ (TANAKA et al., 2003).

Figura 2. Variabilidade temporal da temperatura do ar e do substrato no interior do coletor solar.

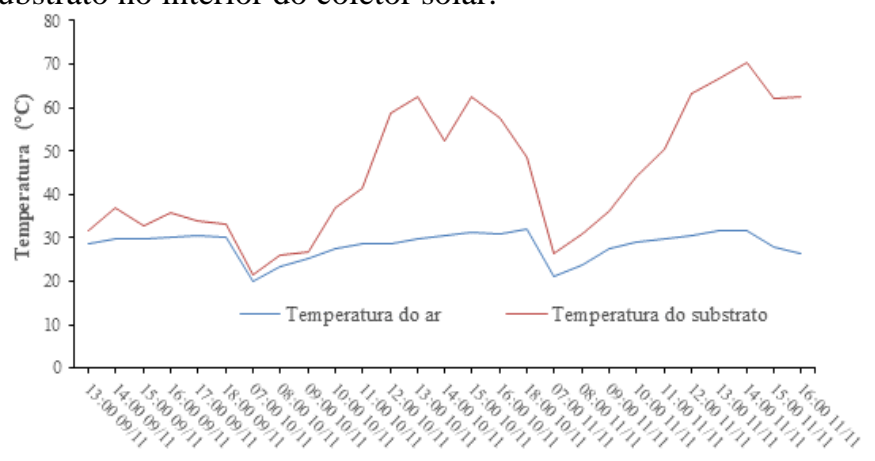

No substrato (Figura 2), a temperatura mínima foi de $21,6^{\circ} \mathrm{C}$, enquanto a máxima e média foram de 70,4 e $44,9{ }^{\circ} \mathrm{C}$, respectivamente.

Estes resultados estão de acordo com os obtidos por Ghini (1997), a qual relatou que as temperaturas máximas variaram entre 70 e $80^{\circ} \mathrm{C}$, em um coletor semelhante ao deste trabalho.
Estas temperaturas máximas podem ser consideradas satisfatórias para o tratamento do substrato, uma vez que seriam suficientes para inativar os patógenos habitantes do solo, como fungos, bactérias e nematoides, conforme relatam Campanhola; Bettiol (2003) e Tanaka et al. (2003).

Observando a Figura 2, pode-se verificar que o coletor solar promoveu uma efetiva elevação da temperatura do substrato no seu interior, quando comparada com a do ar, resultando em uma amplitude térmica mínima de $1,2^{\circ} \mathrm{C}$ e uma máxima de $38,6^{\circ} \mathrm{C}$, sendo a temperatura média de $16,5^{\circ} \mathrm{C}$.

Essa rápida e significativa elevação da temperatura do substrato no interior deste tipo de coletor solar (Figura 2) é responsável pelo tempo, relativamente curto, necessário para o seu efetivo tratamento, principalmente quando considerado outros métodos térmicos.

Como comparação, a solarização, que consiste no emprego de filme plástico sobre o solo, pode levar até dois meses para que o tratamento seja efetivo (ELMORE et al., 1997).

Essa limitação da solarização acontece porque a inativação térmica de diversos patógenos obedece, geralmente, a um modelo exponencial, sendo que, quanto menor a temperatura, maior será o tempo necessário para a inativação deste. Além disso, quanto maior a profundidade tratada, menores serão também as temperaturas atingidas com a solarização com filme plástico (GHINI, 1997; MORMILE et al., 2016).

Nos coletores semelhantes ao utilizado neste estudo, a espessura máxima da camada tratada é relativamente pequena, correspondendo ao raio dos tubos, de $0,075 \mathrm{~m}$. Isso, se for assumido que o aquecimento da secção circular, transversal, do tubo e, consequentemente, do substrato, ocorre da sua periferia para o seu centro, o que favoreceria o tratamento rápido do substrato.

No caso da solarização, o aquecimento do solo ocorre predominantemente em um único sentido, da superfície para a subsuperfície, reduzindo-se a temperatura à medida que se aprofunda no solo, exigindo-se assim longos períodos de exposição aos raios solares para que o tratamento seja efetivo.

Os efeitos da radiação incidente sobre a elevação da temperatura do substrato, no interior do coletor solar é ilustrado pela Figura 3. 
Figura 3. Elevação da temperatura por unidade de radiação solar recebida pelo substrato no interior do coletor solar

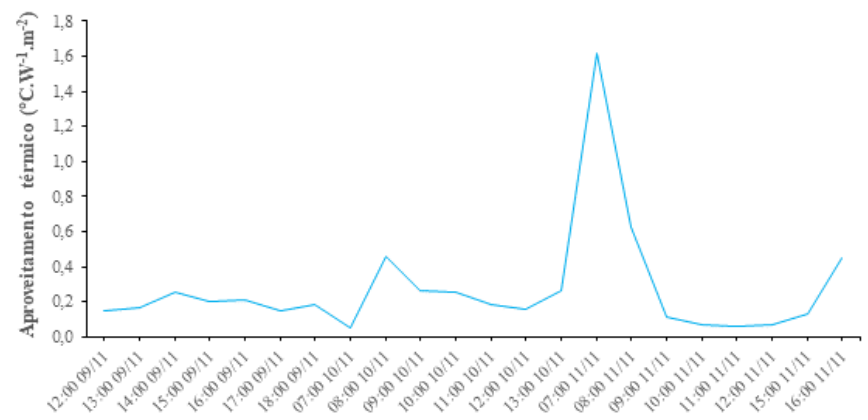

Como pode ser observado na Figura 3, o coletor solar permitiu um aproveitamento térmico da energia solar capaz de elevar a temperatura do substrato em até $0,28{ }^{\circ} \mathrm{C}$, por cada unidade de irradiância recebida $\left(\mathrm{W} \cdot \mathrm{m}^{2}\right)$, sendo os valores, mínimo e médio, correspondentes a 0,05 e $1,61^{\circ} \mathrm{C} . \mathrm{W}^{-1} \cdot \mathrm{m}^{-2}$, respectivamente.

Nota-se também na Figura 3 que houve uma significativa variabilidade no aproveitamento térmico da energia solar pelo coletor solar, o que pode ser explicado, em parte, pelo fato de que a eficiência da transferência de calor entre corpos separados por um meio interveniente, como a atmosfera, é influenciada diretamente pelo próprio meio, que pode absorver, refletir e dispersar parte da energia disponível (PELLEGRINI, 2019).

Com relação ao desempenho do coletor solar no tratamento do substrato, constatou-se a exposição do equipamento a radiação solar por duas horas foi suficiente para desinfestar o mesmo, conforme demonstra a Figura 4.

Figura 4. Quantidade média de grilos sobreviventes e respectivos tratamentos. Médias seguidas de mesmas letras não diferem entre si pelo teste de Tukey, ao nível de 5\% de probabilidade.

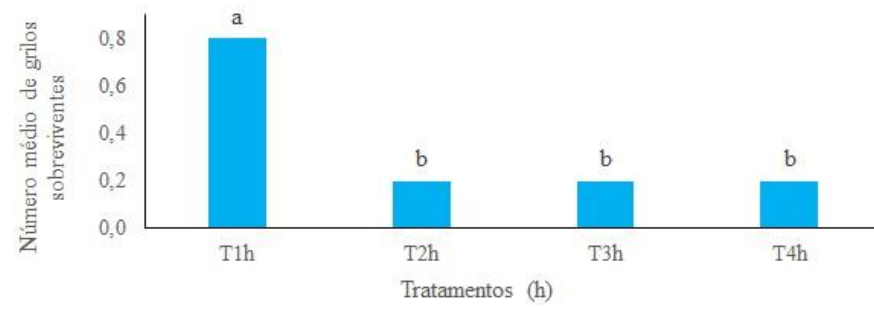

Considerando o número de horas, necessário para que outros tratamentos alternativos com energia solar, promovam a desinfestação do substrato (GHINI, 1997), pode-se constatar que o coletor solar em questão apresenta um desempenho muito superior a estes, ao necessitar de, no máximo, duas horas para a mesma operação (Figura 4).

De fato, o equipamento permitiu a elevação da temperatura do substrato tratado em $35,4{ }^{\circ} \mathrm{C}$, em média, quando comparada a temperatura do substrato testemunha, sendo capaz de manter uma temperatura média de $60,4^{\circ} \mathrm{C}$, ao longo do experimento.

Ainda que sejam materiais distintos, pode-se citar o desempenho de coletores solar na desinfestação de pragas, em armazenamento de grãos, como relatam Mekasha et al. (2006) sobre a eficácia deste tipo de equipamento na desinfestação de carunchos Callosobruchus maculatus (Fabricius) (Coleoptera:
Bruchidae), do feijão Adzuki, em temperaturas atingidas de até $80,7^{\circ} \mathrm{C}$

Ao se estudar o emprego de coletor solar na desinfestação de coleóptera Tribolium castaneum (Herbst), em sementes de cacau, Abdullahi et al. (2017) afirmaram que a mortalidades nas populações tratadas variaram de 96,66 a $100 \%$.

Portanto, os resultados obtidos neste experimento demonstram a efetividade desse tipo de coletor solar na desinfestação do substrato com grilo-preto, em um intervalo de tempo relativamente curto, tornando-se uma alternativa a mais para o controle complexo, dispendioso e ineficaz desta praga, em certas condições, (SALVADORI et al., 2007; MOREIRA; ARAGÃO, 2009; SANTOS et al., 2008), principalmente se considerado os locais de difícil acesso, como os esconderijos típicos do inseto e/ou a ausência de predadores naturais.

\section{CONCLUSÕES}

O desempenho térmico do coletor solar indicou que a temperatura máxima do substrato foi de $70,4{ }^{\circ} \mathrm{C}$, com uma amplitude térmica máxima de $38,6^{\circ} \mathrm{C}$, entre o interior e exterior do equipamento, sendo o aproveitamento térmico igual a 0,28 ${ }^{\circ} \mathrm{C} . \mathrm{W}^{-1} \cdot \mathrm{m}^{-2}$.

São necessárias duas horas para desinfestar o substrato do grilo-preto, quando a temperatura média interna era de $60,4^{\circ} \mathrm{C}$, com o substrato testemunha, situado em local protegido da radiação solar, atingindo $25,0^{\circ} \mathrm{C}$ em média.

\section{AGRADECIMENTO(S)}

À Fundação de Amparo à Pesquisa de Minas Gerais FAPEMIG, pelo apoio financeiro.

\section{REFERÊNCIAS}

ABDULLAHI, G.; MUHAMAD, R.; DZOLKHIFLI, O.; SINNIAH, U. R. Disinfestation of cocoa beans infested with life stages of Tribolium castaneum (Herbst) (Coleoptera: Tenebrionidae) using solar heat trapped in a cardboard solar heater box. Journal of Entomology and Zoology Studies, v. 5, v.6, p. 226-233, 2017

BARBOSA, L. R.; IEDE, E. T.; SANTOS, F. Biologia, caracterização de danos e ocorrência de grilos em plantios de eucalipto. Colombo: Embrapa Florestas, 2009. 27 p. (Embrapa Florestas. Documentos, 189).

BRASIL. Empresa de Pesquisa Energética. Balanço Energético Nacional 2019: Ano base 2018. Rio de Janeiro: EPE, 2019. 292 p.

CAMPANHOLA, C.; BETTIOL, W. Métodos alternativos de controle fitossanitário. Jaguariúna: Embrapa Meio Ambiente; 2003. $279 \mathrm{p}$.

CARVALHO, S. A.; GIRARDI, E. A.; MOURÃO FILHO, F. A. A.; FERRAREZI, R. S.; COLETTA FILHO, H. D. Advances in citrus propagation in Brazil. Revista Brasileira de Fruticultura, v. 41, n. 6, p. 1-36, 2019. 10.1590/0100-29452019422

COELHO, T. A. V.; SOARES, I. D.; DUIN, I. M.; REZENDE, E. H.; AUER, C. G.; SANTOS, A. F. Etiologia da mortalidade de miniestacas de Eucalyptus benthamii e possíveis fontes de 
inóculo. Summa Phytopathologica. Jul; v. 45, n. 2, p. 157-163, 2019. 10.1590/0100-5405/191788

COLOMBARI, L. F.; BALDINI, L. F. G.; SILVA, F. Z.; ONO, E. O.; RODRIGUES, J. D.; GOTO, R. Controle químico da hérnia das crucíferas em rúcula cultivada em campo naturalmente infestado. Revista de Ciências Agrárias, v. 41, n. 4, p. 1083-1089, 2018. 10.19084/RCA17178

ELMORE, C. L.; STAPLETON, J. J.; BELL, C. E.; DEVAY, J. E. Soil Solarization: A Nonpesticidal Method for Controlling Diseases, Nematodes, and Weeds. Oakland (EUA): University of California; 1997. 17 p.

FACÃO, J. M. R. V. Estudo de colectores solares incorporando tubos de calor com aplicação em ciclos motores. 2004. 158 p. Tese (Doutorado em Engenharia Mecânica) Universidade do Porto, Porto (PT). 2004.

GHINI, R. Desinfestação do solo com uso de energia solar: solarização e coletor solar. Jaguariúna: Embrapa-CNPMA; 1997. 29 p.

FERREIRA, D. F. SISVAR: a computer analysis system to fixed effects split plot type designs. Revista Brasileira de Biometria, [S.1.], v. 37, n. 4, p. 529-535, dec. 2019. 10.28951/rbb.v37i4.450.

KHAN, R.; NAZ, I.; HUSSAIN, S.; KHAN, R. A. A.; ULLAH, S.; RASHID, M. U.; SIDDIQUEA, I. Phytochemical management of root knot nematode (Meloidogyne incognita) kofoid and white chitwood by Artemisia spp. in tomato (Lycopersicon esculentum L.). Brazilian Journal of Biology, v. 80, n. 4, p. 1-10, 2020. 10.1590/1519-6984.222040

MAFIA, R. G; ALFENAS, A. C.; FERREIRA, M. A. Avaliação da resistência do eucalipto à murcha-bacteriana causada por Ralstonia solanacearum. Revista Árvore, v. 38, n. 4, p. 649-656, 2014. 10.1590/S0100-67622014000400008

MASSON, M. V.; TAVARES, W. S.; ALVES, J. M.; FERREIRA-FILHO, P. J.; BARBOSA, L. R.; WILCKEN, C. F.; ZANUNCIO, J. C. Bioecological aspects of the common black field cricket, Gryllus assimilis (Orthoptera: Gryllidae) in the laboratory and in Eucalyptus (Myrtaceae) plantations. Journal of Orthoptera Research, v. 29, n. 1, p. 83-89, 2020. 10.3897/jor.29.48966

MEKASHA, C.; DZOLKIFLI, O.; YUSUF, S.; RITA, M.; NOORMA, O. Development of efficient solar heaters for storage insect pest management. African Crop Science Journal, v. 14, n. 3, p. 253-261, 2006. 10.15547/ast.2019.03.043

MICHEREFF FILHO, M.; RESENDE, F. V.; VIDAL, M. C.; GUIMARAES, J. A.; MOURA, A. P.; SILVA, P. S.; REYES, C. P. Manejo de pragas em hortaliças durante a transição agroecológica. Brasília, DF: Embrapa Hortaliças, 2013. 16 p. (Embrapa Hortaliças. Circular técnica, 119).

MIRANDA, G. R. B.; GUIMARÃES, R. J., BOTREL, E. P.; CAMPOS, V. P.; ALMEIDA, G. R. R.; GONZALEZ, R. G. Formação de mudas de cafeeiro em substratos oriundos de diferentes métodos de desinfestação. Bragantia, v. 65, n. 2, p. 303-307, 2006. 10.1590/S0006-87052006000200012
MOREIRA, H. J. C.; ARAGÃO, F. D. Manual de Pragas do Milho. Campinas (BR): Agrolink, 2009. 132 p.

MORMILE, P.; RIPPA, M.; PETTI, L.; IMMIRZI, B.; MALINCONICO, M.; LAHOZ, E.; MORRA, L. Improvement of Soil Solarization through a Hybrid System Simulating a Solar Hot Water Panel. Journal of Advanced Agricultural Technologies, v. 3, n. 3, p. 226-230, 2016. 10.18178/joaat.3.3.226-230

OLIVEIRA, D. A. Análise geoambiental da bacia hidrográfica do rio Perdizes - Minas Gerais. 2010. 122 p. Monografia (Graduação em Geografia) - Universidade Federal de Uberlândia, Uberlândia, 2010.

PELLEGRINI, C. C. A busca pelo copo ideal: um estudo de otimização em transferência de calor. Revista Brasileira de Ensino de Física, v. 41, n. 3, 2019.. 10.1590/1806-9126-RBEF2018-0234

PEREIRA, E. B.; MARTINS, F. R.; ABREU, S. L.; RÜTHER, R. Atlas Brasileiro de Energia Solar. São José dos Campos: INPE, 2006. 60p.

POLETTO, I.; MUNIZ, M. F. B.; CECONI, D. E.; POLETTO, T. Aspectos epidemiológicos da podridão-de-raízes da erva-mate (Ilex paraguariensis). Ciência Florestal, v. 25, n. 2, p. 281-291, 2015. $10.5902 / 1980509818445$

SALA, F. C.; COSTA, C. P.; TEIXEIRA, L. D.; FABRI, E. G.; BLAT, S. F. Reação de cultivares de alface a Thielaviopsis basicola. Horticultura Brasileira, v. 26, n. 3, p. 398-400, 2008. 10.1590/S0102-05362008000300021

SALVADORI, J. R.; PEREIRA, P. R. V. S.; CORRÊAFERREIRA, B. S. Pragas ocasionais em lavouras de soja no Rio Grande do Sul. Passo Fundo: Embrapa Trigo, 2007. 34 p. (Embrapa Trigo. Documentos Online, 91).

SANTOS, G. P.; ZANUNCIO, J. C.; ZANUNCIO, T. V.; PIRES, E. M. Pragas de eucalipto. Informe Agropecuário, v. 29, n. 242, p. 47-70, 2008.

SOUZA FILHO, J. R. Projeto, construção e levantamento de desempenho de um concentrador solar cilíndro parabólico com mecanismo automático de rastreamento solar. 2008. 76 p. Dissertação. (Mestrado em Engenharia Mecânica) - Centro de Tecnologia, Universidade Federal do Rio Grande do Norte. Natal, 2008.

SOUZA, F. X. Materiais para formulação de substratos na produção de mudas e no cultivo de plantas envasadas. Fortaleza: Embrapa Agroindústria Tropical, 2000. 21p.

TANAKA, M. A. S.; ITO, M. F.; BRAGA, C. A. S.; ARMOND, G. Tratamento térmico solar da água para controle de fitopatógenos. Fitopatologia Brasileira, v. 28, n. 4, p. 386-393, 2003. 10.1590/S0100-41582003000400007

WEIRICH NETO, P. H.; BERGAMINI, Y. A. L.; EURICH, J.; SOUZA, N. M.; ROCHA, C. H. Desidratador de frutas com uso de energia solar direta. Revista Brasileira de Energias Renováveis, v. 5, n. 1, p. 1-11, 2016. 10.5380/rber.v5i1.38402 